\title{
Studi Pemodelan Dengan Analisis Jalur (Path Analysis) Guna Penunjang Keputusan Indeks Kinerja Sistem Irigasi Daerah Irigasi Candi Kabupaten Jember
}

\author{
Arfin Putri Sahdini ${ }^{1 *}$, Rini Wahyu Sayekti ${ }^{1}$, Tri Budi Prayogo ${ }^{1}$ \\ ${ }^{1}$ Jurusan Teknik Pengairan, Fakultas Teknik, Universitas Brawijaya, \\ Jl. MT. Haryono no. 167, Malang, 65145, Indonesia \\ *Korespondensi Email: arfinputri1809@gmail.com
}

\begin{abstract}
Irrigation performance is an indicator to description irrigation system management, Assesment Performance based on Permen PUPR 12/PRT/M/2015 made to the 6 parameters including: Physical Infrastructure, Plant Productivity, Supporting Facilities, Personnel Organization, Documentation and Water User Association (P3A), whereas the assesment is carried out by evaluation method of Masscote with Rapid Appraisal Procedure (RAP) which is a set of systematic procedures to diagnose obstacles, performance and level services in the system irrigation to 4 main indicators include; Service Indicator, P3A Indicator, Human Resource of Operator Indicator, and Channel Operations Modernization indicator, performance assessment are taken by surveyor of respondents Operator irrigation, and farmers P3A, Show performance index by Permen PUPR 12/PRT/M/2015 gave the value 63,16\% which has Less and Need Attention Perfomance Operations and Maintenance of Candi Irrigation, while the Masscote methode show perfomance 3,04 in level of Service which has Well Performance of Service and Operation Irrigation Channels. Based on the path analysis found mathematical modeling with the equation $\mathrm{Y}=0,420 \mathrm{X} 1+0,427 \mathrm{X} 2+0,432 \mathrm{X} 3$ $-0,446 \mathrm{X} 4$, with $\mathrm{R}^{2} 0,857$ or $85,7 \%$. Where the significant influence with 4 main indicator variables $\mathrm{X}_{1}, \mathrm{X}_{2}, \mathrm{X}_{3}$ and $\mathrm{X}_{4}$ to irrigation system performance variable (Y) of 0,857 or $85,7 \%$.
\end{abstract}

Keywords: Irrigation System Performance, Masscote, Path Analysis, Rapid Appraisal Procedure (RAP)

Abstrak: Kinerja irigasi menjadi suatu indikasi dalam rangka menggambarkan suatu pengelolaan sistem irigasi, Penilaian kinerja berdasaran Permen PUPR No. 12/PRT/M/2015 dilakukan 6 parameter yaitu; Prasarana Fisik, Produktivitas Tanam, Sarana Penunjang, Organisasi Personalia, Dokumentasi dan Perkumpulan Petani Pemakai Air (P3A), sedangkan pendekatan metode Masscote dilakukan dengan evaluasi Rapid Appraisal Procedure (RAP) yang merupakan seperangkat prosedure sistematis untuk mendiagnosa hambatan, kinerja dan tingkat layanan dalam sistem irigasi terhdap 4 indikator utama yaitu: Indikator Pelayanan, Indikator P3A, Indikator SDM Operator, dan Indikator Modernisasi Operasi Saluran. Penilaian kinerja 
dilakukan melalui survei terhadap petugas OP irigasi dan petani P3A yang menunjukkan indeks kinerja sebesar 63,16\% atau kategori Kurang dan Perlu Perhatian terhadap kinerja Operasi dan Pemeliharaan berdasarkan Permen PUPR No. 12/PRT/M/2015, sedangkan indeks kinerja sebesar 3,04 berdasarkan metode Masscote dengan evaluasi RAP menunjukkan Level of Service pada kategori Baik terhadap kinerja Operasi Saluran dan Pelayanan Irigasi. Berdasarkan analisis jalur (Path Analysis) didapatkan pemodelan matematika dengan persamaan $\mathrm{Y}=0,420 \mathrm{X} 1$ $+0,427 \mathrm{X} 2+0,432 \mathrm{X} 3-0,446 \mathrm{X} 4$, dengan $\mathrm{R}^{2} 0,857$ atau 85,7\%. Dimana pengaruh signifikan secara bersama veariabel indikator utama $X_{1}, X_{2}, X_{3}$ dan $X_{4}$ terhadap variabel kinerja sistem irigasi (Y) sebesar 0,857 atau 85,7\%.

Kata kunci: Analisis Jalur, Kinerja Sistem Irigasi, Metode Masscote, Rapid Appraisal Procedure (RAP)

\section{Pendahuluan}

Negara Indonesia termasuk salah satu negara yang beriklim tropis, maka dari itu lahan-lahan yang ada di Indonesia biasanya sebagian besar dimanfaatkan untuk daerah pertanian. Penurunan kinerja sistem irigasi disebabkan karena menurunnya produksi pertanian pada suatu wilayah. Salah satu hal yang menyebabkan kekurangan pangan di negara Indonesia adalah menurunnya produksi pertanian [1]. Oleh karena itu menurut Peraturan menteri PUPR No.12/PRT/M/2015 Pemeliharaan jaringan irigasi merupakan upaya menjaga dan mengamankan jaringan irigasi agar selalu dapat berfungsi dengan baik guna memperlancar pelaksanaan operasi jaringan irigasi dan mempertahankan kelestariannya [2].

Berdasarkan pengamatan di lapangan, hasil permasalahan yang terjadi pada Daerah Irigasi (DI) Candi yaitu banyaknya kondisi bangunan dan saluran yang mengalami kerusakan akibat kurang perawatan dari pihak yang terkait dan juga akibat ulah masyarakat setempat yang sengaja merusak maupun mencuri perangkat bangunan. Kerusakan yang sering terjadi yaitu pada pengukur debit, pintu, tubuh bangunan dan lining saluran. Sehingga dapat membuat kinerja pembagian air irigasi pada jaringan irigasi sangat terganggu.

Tujuan dari penelitian ini yaitu mengetahui indeks kinerja sistem irigasi Daerah Irigasi Candi berdasarkan Permen PUPR No.12/PRT/M/2015, mengetahui hasil pemodelan matematika berdasarkan analisis jalur (Path Analysis) pada Daerah Irigasi Candi, serta mengetahui hasil keputusan kinerja sistem irigasi Daerah Irigasi Candi yang didukung oleh Metode MASSCOTE [3].

\section{Bahan dan Metode}

\subsection{Bahan}

Penelitian dilakukan di Daerah Irigasi Candi terletak di Desa Petung yang merupakan salah satu desa di Kecamatan Bangsalsari dengan luasan 13,32 km² dan total luas Kecamatan Bangsalsari yaitu seluas $166,78 \mathrm{~km}^{2}$.

Data dari penelitian ini membutuhkan data-data yang mendukung dalam pengerjaannya. Datadata yang diperlukan yaitu sebagai berikut:

- Data Primer. Data primer yaitu data yang didapatkan dari hasil pengamatan secara langsung di lapangan seperti data bangunan utama, data saluran pembawa, data bangunan bagi/sadap, data saluran pembuang dan data bangunan pada saluran pembuang [4]. 
- Data Sekunder. Data sekunder yaitu data yang didapatkan dari suatu lembaga atau instansi terkait dan juga dari kutipan sumber yang sebenarnya dapat dipertanggung jawabkan [4].

- Data Inventarisasi. Data inventarisasi berfungsi untuk mengidentifikasi kondisi kinerja sistem irigasi yang meliputi kondisi bangunan dan kondisi saluran irigasi yang berada di seluruh saluran sekunder dan tersier [5].

- Penilaian Kinerja Sistem Irigasi dengan Permen PUPR No.12/PRT/M/2015. Penilaian kinerja sistem irigasi dinilai berdasarkan 6 parameter yang meliputi prasarana fisik (45\%), produktivitas tanam (15\%), sarana pendukung (10\%), organisasi personalia (15\%), dokumentasi (5\%), dan Perkumpulan Petani Pemakai Air (P3A) (10\%) [6].

- Penilaian Kinerja Sistem Irigasi dengan Metode MASSCOTE. Penilaian kinerja sistem irigasi dinilai berdasarkan 4 indikator utama yang meliputi indikator pelayanan, indikator P3A, indikator SDM operator dan indikator modernisasi operasi saluran [7].

- Pemodelan Analisis Jalur (Path Analysisi). Analisis Jalur (Path Analysis) digunakan untuk menganalisis pola hubungna antar variabel yang bertujuan untuk mengetahui hubungan langsung maupun tidak langsung [7].

- Analisis Data. Data yang didapatkan dalam penelitian yaitu data dari 4 indikator utama yang meliputi indikator pelayanan, indikator P3A, indikator SDM operator dan indikator modernisasi operasi saluran. Analisis yang dilakukan yaitu menggunakan analisis jalur atau Path Analysis. Path Analysis bertujuan untuk mengetahui besar pengaruh dari 4 (empat) indikator utama dalam penilaian kinerja sistem irigasi [7].

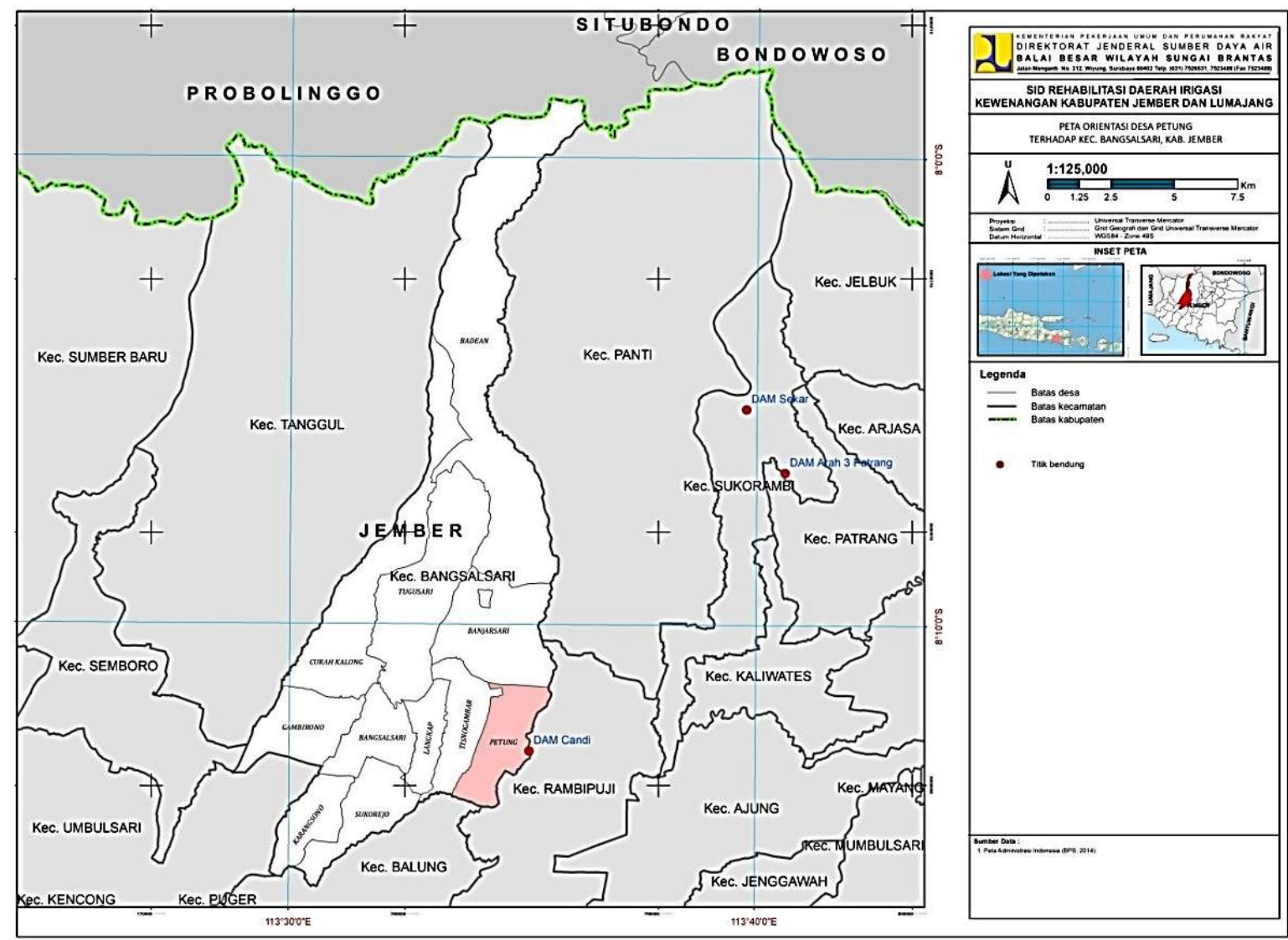

Gambar 1: Peta Lokasi Studi 
2.2 Metode

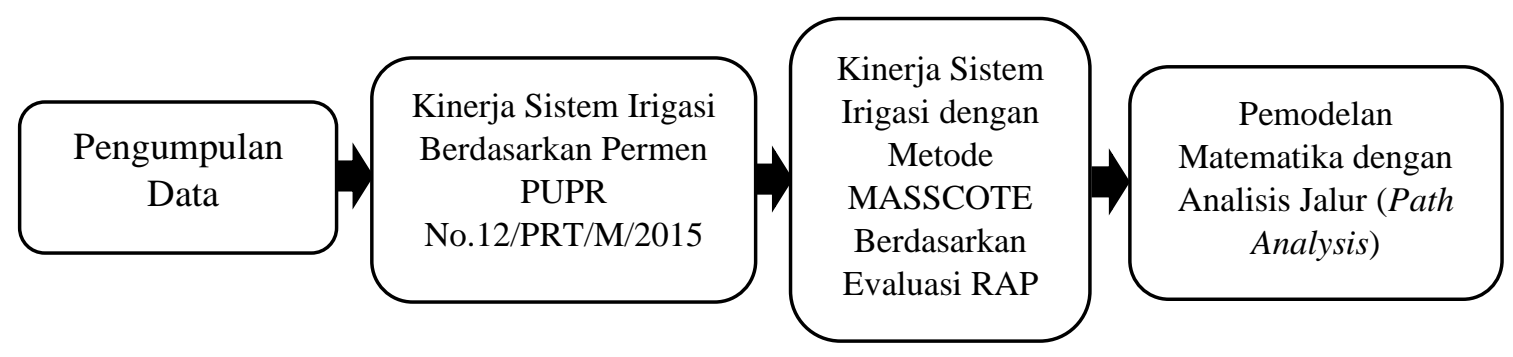

Data yang diperlukan untuk tahapan penelitian pada studi ini meliputi: data primer, data sekunder, dan data koesioner yang sudah dibagikan kepada responden. Kemudian dari data primer dan data sekunder didapatkan penilaian kinerja sistem irigasi berdasarkan Permen PUPR No.12/PRT/M/2015. Penilaian kinerja sistem irigasi dinilai berdasarkan 6 parameter yang meliputi: prasarana fisik, produktivitas tanam, sarana pendukung, organisasi personalia, dokumentasi dan P3A. Dan dari data koesioner yang sudah dibagikan kepada responden didapatkan penilaian kinerja sistem irigasi dengan Metode MASSCOTE berdasarkan evaluasi Rapid Appraisal Procedure (RAP). Penilaian kinerja sistem irigasi dengan Metode MASSCOTE ini dinilai berdasarkan 4 indikator utama yang meliputi: indikator pelayanan, indikator P3A, indikator SDM operator dan indikator modernisasi operasi saluran. Sehingga dari hasil indeks kinerja sistem irigasi dengan Metode MASSCOTE didapatkan pemodelan Matematika dengan Analisis Jalur (Path Analysis).

\subsection{Persamaan}

\subsubsection{Pemodelan dengan Analisis Jalur (Path Analysis)}

Adapun bentuk persamaan jalurnya yaitu sebagai berikut:

$$
Y=\rho y x_{1} X_{1}+\rho y x_{2} X_{2}+\rho y x_{3} X_{3}+\rho y x_{4} X_{4}+\varepsilon
$$

Pers. 1

Dimana:

$\mathrm{Y}$

$\mathrm{X}_{1}$

$\mathrm{X}_{2}$

$\mathrm{X}_{3}$

$\mathrm{X}_{4}$

$\varepsilon$

$$
\begin{aligned}
& =\text { Kinerja sistem irigasi } \\
& =\text { Indikator pelayanan irigasi } \\
& =\text { Indikator petani P3A } \\
& =\text { Indikator SDM Operator Saluran } \\
& =\text { Koefisien jalur antara variabel akibat dan variabel penyebab } \\
& =\text { Variabel residual }
\end{aligned}
$$

\subsubsection{Uji Hipotesis Secara Keseluruhan}

$\mathrm{H}_{0}: \rho \mathrm{yx}_{1}=\rho \mathrm{yx}_{2}=\ldots=\rho \mathrm{yx}_{\mathrm{k}}$

$\mathrm{H}_{1}$ : ada salah satu $\rho \mathrm{yx}_{\mathrm{n}}$

\subsubsection{Uji Signifikansi Koesioner Jalur}

Uji ini bertujuan untuk menguji hipotesis penelitian 1,2 dan 3 dengan kriteria pengambilan keputusan sebagai berikut:

- $\quad$ Jika nilai $\mathrm{p}_{\mathrm{ij}}<0,05$ (koefisien jalur $\mathrm{p}_{\mathrm{ij}}$ tidak signifikan) maka $\mathrm{H}_{0}$ diterima dan $\mathrm{H}_{1}$ ditolak.

- $\quad$ Jika nilai $\mathrm{p}_{\mathrm{ij}}>0,05$ (koefisien jalur $\mathrm{p}_{\mathrm{ij}}$ signifikan) maka $\mathrm{H}_{0}$ ditolak dan $\mathrm{H}_{1}$ diterima. 


\section{Hasil dan Pembahasan}

\subsection{Penilaian Kinerja Sistem Irigasi Daerah Irigasi Candi Berdasarkan Permen PUPR No.12/PRT/M/2015}

Penilaian kinerja irigasi berdasarkan Permen PU No.12/PRT/M/2015 melalui observasi lapangan dan wawancara dengan petugas tersaji dalam Tabel 1.

Tabel 1: Data Penilaian Kinerja Irigasi Berdasarkan Permen PUPR No.12/PRT/M/2015

\begin{tabular}{|c|c|c|c|}
\hline Uraian & $\begin{array}{l}\text { Nilai } \\
\text { Bobot }\end{array}$ & $\begin{array}{c}\text { Nilai } \\
\text { Kondisi } \\
\text { Fisik } \\
(\mathrm{NKF}) \\
3\end{array}$ & $\begin{array}{c}\text { Nilai } \\
\text { Kondisi } \\
\text { Bobot } \\
(\mathrm{NKB}) \\
4=(2 \times 3) / 100\end{array}$ \\
\hline 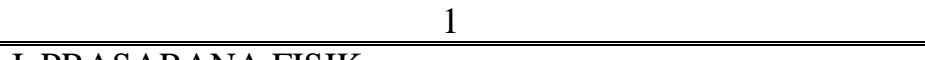 & $\frac{2}{2}$ & 3 & $4=(2 \times 3) / 100$ \\
\hline I. PRASARANA FISIK & 45,00 & & 28,38 \\
\hline 1. Bangunan Utama & 13,00 & & 9,70 \\
\hline 1.1. Bendung & 4,00 & & 2,82 \\
\hline a.Mercu & 0,80 & 90,00 & 0,72 \\
\hline b.Sayap & 0,60 & 85,00 & 0,51 \\
\hline c.Lantai bendung & 0,80 & 90,00 & 0,72 \\
\hline d. Tanggul penutup & 0,80 & 90,00 & 0,72 \\
\hline e.Jembatan & 0,20 & 0,00 & 0,00 \\
\hline f.Papan untuk operasi & 0,40 & 0,00 & 0,00 \\
\hline g.Mistar ukur & 0,20 & 73,00 & 0,15 \\
\hline h.Pagar pengaman & 0,20 & 0,00 & 0,00 \\
\hline $\begin{array}{l}\text { 1.2. Pintu-pintu dalam bendung dan roda gigi dapat } \\
\text { dioperasikan. }\end{array}$ & 7,00 & & 5,78 \\
\hline a. Pintu pengambilan & 3,50 & 90,00 & 3,15 \\
\hline b. Pintu penguras Bendung & 3,50 & 75,00 & 2,63 \\
\hline 1.3. Kantong lumpur\& Pintu Pengurasnya & 2,00 & & 1,11 \\
\hline a. Bangunan kantong lumpur baik & 0,70 & 90,00 & 0,63 \\
\hline b. Kantong lumpur telah di bersihkan & 0,60 & 80,00 & 0,48 \\
\hline $\begin{array}{l}\text { c. Pintu penguras \& roda gigi kantong lumpur } \\
\text { dapat dioperasikan }\end{array}$ & 0,70 & 0,00 & 0,00 \\
\hline 2. Saluran Pembawa & 10,00 & & 7,70 \\
\hline $\begin{array}{l}\text { 2.1. Kapasitas tiap saluran cukup untuk membawa } \\
\text { debit kebutuhan /rencana }\end{array}$ & 5,00 & 80,00 & 4,00 \\
\hline $\begin{array}{l}\text { 2.2. Tinggi tanggul cukup untuk menghindari limpahan } \\
\text { setiap saat selama pengoperasian }\end{array}$ & 2,00 & 80,00 & 1,60 \\
\hline 2.3. Semua perbaikan saluran telah selesai & 3,00 & 70,00 & 2,10 \\
\hline 3. Bangunan Pada Saluran Pembawa & 9,00 & & 4,68 \\
\hline $\begin{array}{l}\text { 3.1. Bangunan pengatur (Bagi/Bagi Sadap/Sadap) } \\
\text { lengkap dan berfungsi }\end{array}$ & 2,00 & & 0,64 \\
\hline $\begin{array}{l}\text { a. Setiap saat dan setiap bangunan pengatur perlu } \\
\text { saluran induk dan sekunder }\end{array}$ & 1,00 & 63,75 & 0,64 \\
\hline b. Pada setiap sadap tersier & 1,00 & 0,00 & 0,00 \\
\hline $\begin{array}{l}\text { 3.2. Pengukuran debit dapat dilakukan } \\
\text { dengan rencana pengoperasian DI }\end{array}$ & 2,50 & & 1,70 \\
\hline a. Pada bangunan pengambilan (bendung / intake) & 1,00 & 66,67 & 0,67 \\
\hline $\begin{array}{l}\text { b. Pada setiap bangunan pengatur (Bagi/Bagi } \\
\text { Sadap/Sadap) }\end{array}$ & 0,75 & 66,67 & 0,50 \\
\hline c. Pada setiap sadap untuk tersier & 0,75 & 70,74 & 0,53 \\
\hline 3.3. Bangunan Pelengkap berfungsi dan lengkap & 2,00 & & 1,57 \\
\hline a. Pada saluran induk serta sekunder & 0,80 & 75,01 & 0,60 \\
\hline b. Pada bangunan siphon,gorong-gorong,jembatan & 1,20 & 80,53 & 0,97 \\
\hline
\end{tabular}




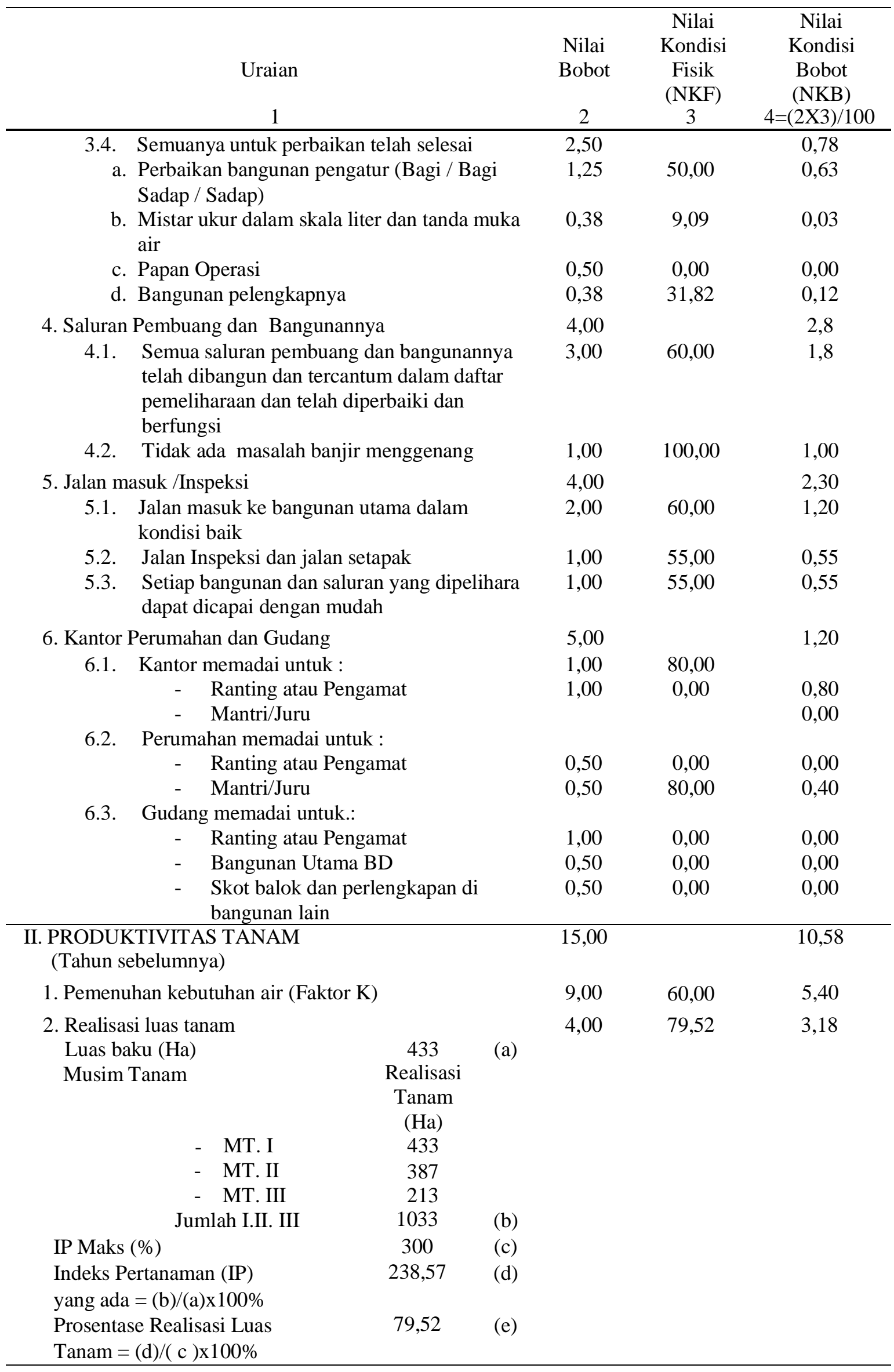




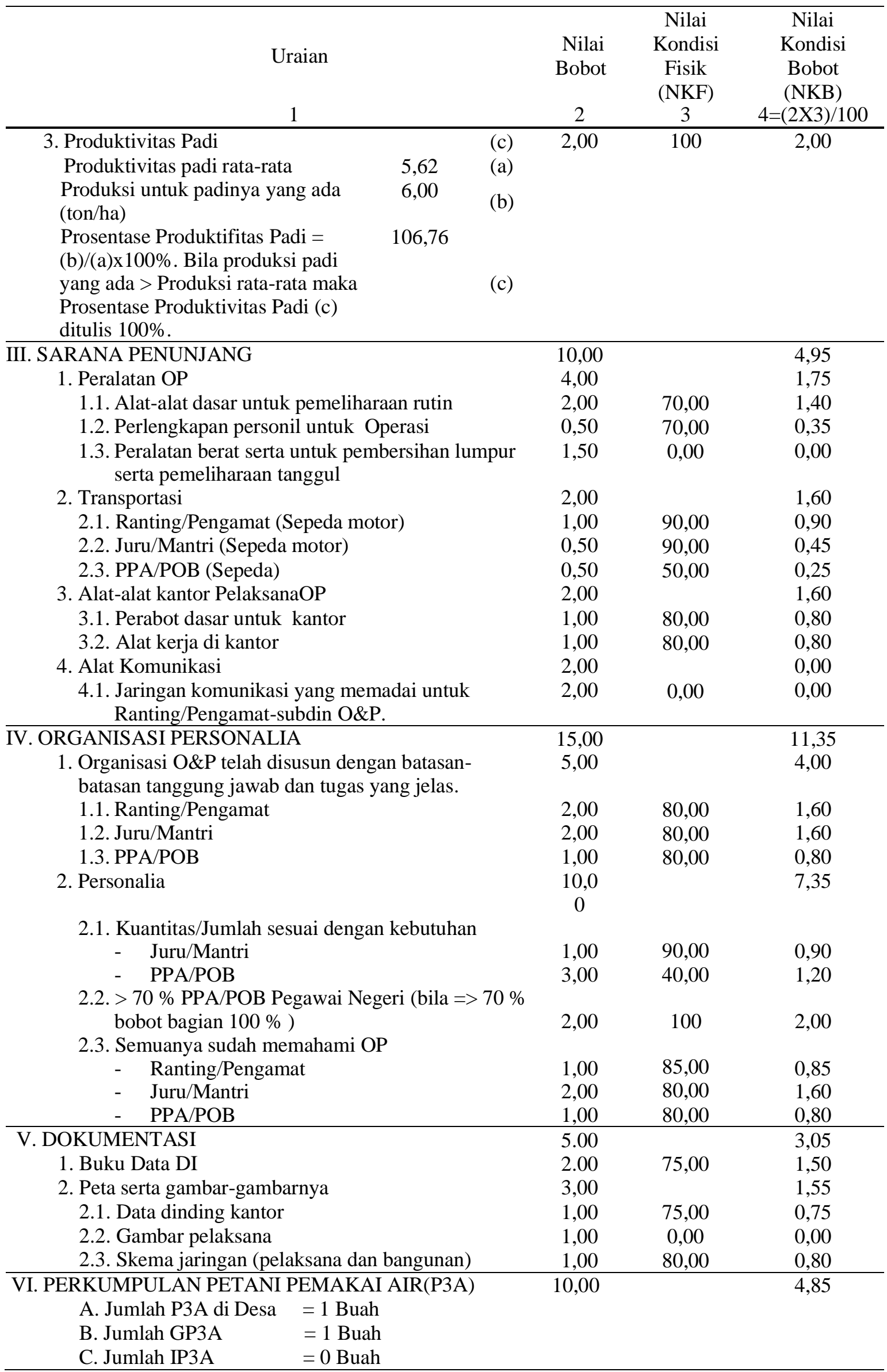




\begin{tabular}{|c|c|c|c|}
\hline Uraian & $\begin{array}{l}\text { Nilai } \\
\text { Bobot }\end{array}$ & $\begin{array}{l}\text { Nilai } \\
\text { Kondisi } \\
\text { Fisik } \\
(\mathrm{NKF})\end{array}$ & $\begin{array}{l}\text { Nilai } \\
\text { Kondisi } \\
\text { Bobot } \\
\text { (NKB) }\end{array}$ \\
\hline 1 & 2 & 3 & $4=(2 \times 3) / 100$ \\
\hline 1. GP3A / IP3A sudah berbadan hukum & 1,50 & 100 & 1,50 \\
\hline $\begin{aligned} \text { 2. } & \text { Kondisi Kelembagaan GP3A / IP3A } \\
- & \text { Berkembang }(100 \%) \\
- & \text { Sedang berkembang }(60 \%) \\
- & \text { Belum Berkembang }(30 \%)\end{aligned}$ & 0,50 & 30,00 & 0,15 \\
\hline 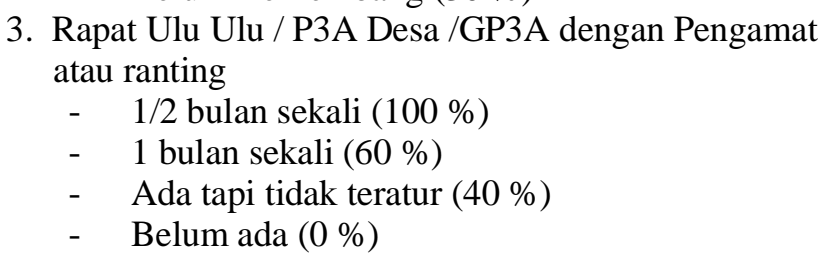 & 2,00 & 40,00 & 0,80 \\
\hline 4. P3A aktif dalam survey/penelusuran jaringan & 1,00 & 60,00 & 0,60 \\
\hline $\begin{array}{l}\text { 5. Partisipasi P3A dalam memperbaiki jaringan serta } \\
\text { penanganan bencana alam. }\end{array}$ & 2,00 & 60,00 & 1,20 \\
\hline 6. Iuran $\mathrm{P} 3 \mathrm{~A}$ digunakan untuk perbaikan jaringan & 2,00 & 0,00 & 0,00 \\
\hline $\begin{array}{l}\text { 7. Partisipasi P3A dalam perencanaan Tata Tanam dan } \\
\text { pengalokasian air }\end{array}$ & 1,00 & 60,00 & 0,60 \\
\hline
\end{tabular}

Tabel 2: Rekapitulasi Penilaian Kinerja Sistem Irigasi Metode Permen PUPR No.12/PRT/M/2015

\begin{tabular}{ccccc}
\hline \multirow{2}{*}{$\begin{array}{c}\text { No. } \\
{[1]}\end{array}$} & \multirow{2}{*}{ Parameter } & & \multicolumn{2}{c}{ Nilai Kondisi Bobot } \\
\cline { 4 - 5 } & {$[2]$} & & Hasil Perhitungan \% & $\begin{array}{c}\text { Bobot Maks \% } \\
{[3]}\end{array}$ \\
\hline 1 & Prasarana Fisik & $:$ & 28,38 & 45 \\
2 & Produktivitas Tanam & $:$ & 10,58 & 15 \\
3 & Sarana Penunjang & $:$ & 4,95 & 10 \\
4 & Organisasi Personalia & $:$ & 11,35 & 15 \\
5 & Dokumentasi & $:$ & 3,05 & 5 \\
6 & P3A & $:$ & 4,85 & 10 \\
\hline \multicolumn{2}{c}{ JUMLAH } & $:$ & 63,16 & 100 \\
\hline
\end{tabular}

Hasil perhitungan penilaian kinerja sistem irigasi Daerah Irigasi (DI) Candi menunjukkan nilai sebesar 63,16\% (nilai maksimum 100\%), berdasarkan pedoman permen PUPR No.12/PRT/M/2015 masuk dalam kategori kinerja kurang dan perlu perhatian. Hal yang menyebabkan kinerja kurang dan perlu perhatian adalah parameter P3A dengan nilai kondisi eksisting 4,85\%, parameter sarana penunjang dengan nilai kondisi eksisting $4,95 \%$ dan parameter dokumentasi dengan nilai kondisi eksisting $3,05 \%$.

Pada parameter P3A yang menyebabkan kinerja dalam kondisi kurang dan perlu perhatian yaitu dari hasil wawancara tidak memiliki jadwal pertemuan rutin serta rapat hanya dilakukan jika memasuki masa tanam untuk membahas rencana tanam, kebutuhan air dan pengalokasian air. Selain hal tersebut, anggota P3A juga tidak pernah melakukan iuran P3A yang bertujuan untuk perbakan jaringan.

Pada parameter sarana penunjang yang menyebabkan kinerja dalam kondisi kurang dan perlu perhatian yaitu tidak adanya perlatan berat untuk pembersihan lumpur dan pemeliharaan tanggul, kondisi alat transportasi untuk sepeda yang kurang baik, dan belum tersedianya alat komunikasi dikarenakan kurangnya jaringan komunikasi yang memadai untuk ranting/pengamat. 
Pada parameter dokumentasi yang menyebabkan kinerja dalam kondisi kurang dan perlu perhatian yaitu tidak tersedianya gambar pelaksana berupa peta pemeliharaan dan gambar bangunan.

\subsection{Penilaian Kinerja dengan Metode MASSCOTE}

Sajian data dalam evaluasi Rapid Appraisal Procedure (RAP) merupakan nilai observasi terhadap responden petugas OP dan petani P3A yang disajikan kedalam kuesioner untuk melakukan cross assesment/ saling menilai antar responden dalam pengelolaan irigasi di Daerah Irigasi Candi. Nilai yang menjadi input dalam RAP adalah nilai median dari penilaian kedua belah pihak (Petugas OP dan Petani P3A) [8].

Tabel 3: Rekapan Penilaian Kinerja Sistem Irigasi Candi Berdasarkan Metode MASSCOTE

\begin{tabular}{|c|c|c|c|c|c|}
\hline $\begin{array}{c}\text { Nama Indikator Utama } \\
{[1]} \\
\end{array}$ & $\begin{array}{c}\text { Penilaian } \\
\text { Indikator } \\
{[2]} \\
\end{array}$ & $\begin{array}{c}\text { Sumber } \\
\text { Informasi Data } \\
{[3]} \\
\end{array}$ & $\begin{array}{c}\text { Nilai } \\
\text { Maksimal } \\
{[4]} \\
\end{array}$ & $\begin{array}{c}\text { (Nilai } \\
\text { Survei) x } \\
\text { (Bobit) } \\
{[5]}\end{array}$ & $\begin{array}{c}\text { Total } \\
\text { Nilai } \\
\text { Bobot } \\
{[6]} \\
\end{array}$ \\
\hline \multicolumn{6}{|c|}{ Pelayanan Berdasarkan Pesanan Pengguna Air Irigasi } \\
\hline $\begin{array}{l}\text { Unit individu misal sawah, bagaimana } \\
\text { layanan pengirimannya? Apakah } \\
\text { teralisasi? }\end{array}$ & 3,15 & $\begin{array}{l}\text { Pengiriman } \\
\text { terakhir }\end{array}$ & 4,00 & 34,69 & 11,00 \\
\hline $\begin{array}{l}\text { Misal untuk sawah apakah ada } \\
\text { rencanan layanan pengiriman untuk } \\
\text { air? }\end{array}$ & 3,19 & $\begin{array}{l}\text { Pertanyaan } \\
\text { Kantor }\end{array}$ & 4,00 & 35,12 & 11,00 \\
\hline $\begin{array}{l}\text { Untuk sawah paling jauh, apakah } \\
\text { pelayanan untuk air terealisasi saat } \\
\text { sistem dioperasikan oleh operator? }\end{array}$ & 3,29 & $\begin{array}{l}\text { Pengiriman } \\
\text { terakhir }\end{array}$ & 4,00 & 55,87 & 17,00 \\
\hline $\begin{array}{l}\text { Untuk sawah paling jauh, apakah ada } \\
\text { rencana layanan pengiriman air oleh } \\
\text { operator? }\end{array}$ & 4,00 & $\begin{array}{l}\text { Pertanyaan } \\
\text { Kantor }\end{array}$ & 4,00 & 68,00 & 17,00 \\
\hline $\begin{array}{l}\text { Apakah ada pesanan air dari petani } \\
\text { atau pengguna air yang dioperasikan } \\
\text { oleh operator? }\end{array}$ & 3,12 & $\begin{array}{l}\text { Pengiriman } \\
\text { terakhir }\end{array}$ & 4,00 & 12,49 & 4,00 \\
\hline Total Nilai I & 16,75 & & 20,00 & & \\
\hline \multicolumn{6}{|c|}{ Saluran Sekunder } \\
\hline $\begin{array}{l}\text { Apakah tersedia Handware atau } \\
\text { perangkat keras untuk mengukur di } \\
\text { saluran sekunder? }\end{array}$ & 2,18 & $\begin{array}{l}\text { Saluran } \\
\text { Tingkat II }\end{array}$ & 4,00 & 4,36 & 2,00 \\
\hline $\begin{array}{l}\text { Apakah tersedia alat komunikasi untuk } \\
\text { operator pengelola irigasi pada saluran } \\
\text { sekunder? }\end{array}$ & 3,16 & $\begin{array}{l}\text { Saluran } \\
\text { Tingkat II }\end{array}$ & 4,00 & 34,77 & 11,00 \\
\hline $\begin{array}{l}\text { Bagaimana untuk kondisi umum } \\
\text { saluran sekunder? }\end{array}$ & 2,21 & $\begin{array}{l}\text { Saluran } \\
\text { Tingkat II }\end{array}$ & 4,00 & 11,05 & 5,00 \\
\hline $\begin{array}{l}\text { Apakah pengoperasian pada saluran } \\
\text { sekunder berjalan dengan lancar? }\end{array}$ & 3,07 & $\begin{array}{l}\text { Saluran } \\
\text { Tingkat II }\end{array}$ & 4,00 & 15,34 & 5,00 \\
\hline Total Nilai II & 10,62 & & 16,00 & & \\
\hline
\end{tabular}




\begin{tabular}{|c|c|c|c|c|c|}
\hline $\begin{array}{c}\text { Nama Indikator Utama } \\
{[1]} \\
\end{array}$ & $\begin{array}{c}\text { Penilaian } \\
\text { Indikator } \\
{[2]} \\
\end{array}$ & $\begin{array}{c}\text { Sumber } \\
\text { Informasi Data } \\
{[3]} \\
\end{array}$ & $\begin{array}{c}\text { Nilai } \\
\text { Maksimal } \\
{[4]} \\
\end{array}$ & $\begin{array}{c}\text { (Nilai } \\
\text { Survei) x } \\
\text { (Bobit) } \\
{[5]} \\
\end{array}$ & $\begin{array}{c}\text { Total } \\
\text { Nilai } \\
\text { Bobot } \\
{[6]} \\
\end{array}$ \\
\hline \multicolumn{6}{|c|}{ Saluran Tersier } \\
\hline $\begin{array}{l}\text { Apakah tersedia handware/perangkat } \\
\text { keras untuk mengukur di saluran } \\
\text { tersier? }\end{array}$ & 2,19 & $\begin{array}{l}\text { Saluran } \\
\text { Tingkat II }\end{array}$ & 4,00 & 4,37 & 2,00 \\
\hline $\begin{array}{l}\text { Bagaimana kondisi bangunan pembagi } \\
\text { di saluran tersier? }\end{array}$ & 3,18 & $\begin{array}{l}\text { Saluran } \\
\text { Tingkat II }\end{array}$ & 4,00 & 9,53 & 3,00 \\
\hline $\begin{array}{l}\text { Apakah ada tersedia alat komunikasi } \\
\text { untuk operator pengelola irigasi pada } \\
\text { saluran tersier? }\end{array}$ & 3,23 & $\begin{array}{l}\text { Saluran } \\
\text { Tingkat II }\end{array}$ & 4,00 & 35,56 & 11,00 \\
\hline $\begin{array}{l}\text { Bagaimana kondisi umum tingkat } \\
\text { saluran tersier? }\end{array}$ & 3,18 & $\begin{array}{l}\text { Saluran } \\
\text { Tingkat II }\end{array}$ & 4,00 & 15,89 & 5,00 \\
\hline $\begin{array}{l}\text { Apakah pengoperasian bangunan pada } \\
\text { saluran tersier berjalan dengan baik? }\end{array}$ & 3,08 & $\begin{array}{l}\text { Saluran } \\
\text { Tingkat II }\end{array}$ & 4,00 & 15,39 & 5,00 \\
\hline Total Nilai III & 14,85 & & 20,00 & & \\
\hline \multicolumn{6}{|c|}{ SDM Pengelola Irigasi dan P3A/GP3A } \\
\hline Bagaimana kondisi karyawa/operator? & 3,09 & Karyawan & 4,00 & 29,38 & 9,50 \\
\hline Bagaimana kondisi WUA/GP3A? & 3,12 & P3A & 4,00 & 20,29 & 6,50 \\
\hline $\begin{array}{l}\text { Apakah mobilitas serta staf operasinya } \\
\text { baik? }\end{array}$ & 3,15 & $\begin{array}{l}\text { Pertanyaan } \\
\text { Kantor }\end{array}$ & 4,00 & 3,15 & 1,00 \\
\hline $\begin{array}{l}\text { Apakah tersedia komputer untuk } \\
\text { mencatat manajemen? }\end{array}$ & 3,09 & $\begin{array}{l}\text { Pertanyaan } \\
\text { Kantor }\end{array}$ & 4,00 & 3,09 & 1,00 \\
\hline $\begin{array}{l}\text { Apakah tersedia komputer untuk } \\
\text { mengontrol saluran? }\end{array}$ & 3,07 & $\begin{array}{l}\text { Pertanyaan } \\
\text { Kantor }\end{array}$ & 4,00 & 3,07 & 1,00 \\
\hline Total Nilai IV & 15,53 & & 20,00 & & \\
\hline \multicolumn{6}{|c|}{ Indikator Modernisasi Operasi Saluran Irigasi } \\
\hline $\begin{array}{l}\text { Apakah kemampuan eksisting dari } \\
\text { layanan berjalan dengan baik? }\end{array}$ & 3,07 & $n / a$ & 4,00 & 9,21 & 3,00 \\
\hline $\begin{array}{l}\text { Apakah perlu melakukan perubahan } \\
\text { operasi saluran diperlukan agar dapat } \\
\text { mendukung modernisasinya? }\end{array}$ & 3,09 & $n / a$ & 4,00 & 6,17 & 2,00 \\
\hline Total Nilai V & 6,16 & & 8,00 & & \\
\hline Total Nilai (I + II + III + IV + V) & 63,91 & & 84,00 & & \\
\hline $\begin{array}{c}\text { Rata-rata Prosentase (\%) Indikator } \\
\text { Internal }\end{array}$ & 0,76 & & & & \\
\hline Nilai Mutlak (Service of Level) & 3,04 & & & & \\
\hline
\end{tabular}


Rekapitulasi penilaian kinerja sistem irigasi Candi berdasarkan metode MASSCOTE dengan evaluasi RAP menunjukkan indeks kinerja sebesar 3,04. Level of Service dalam metode MASSCOTE memberikan kategori sebagai berikut [9]:
a) $4 \quad$ : Terbaik
b) $3-3,9$ : Baik
c) $2-2,9$ : Kurang Baik
d) $1-1,9 \quad$ : Buruk

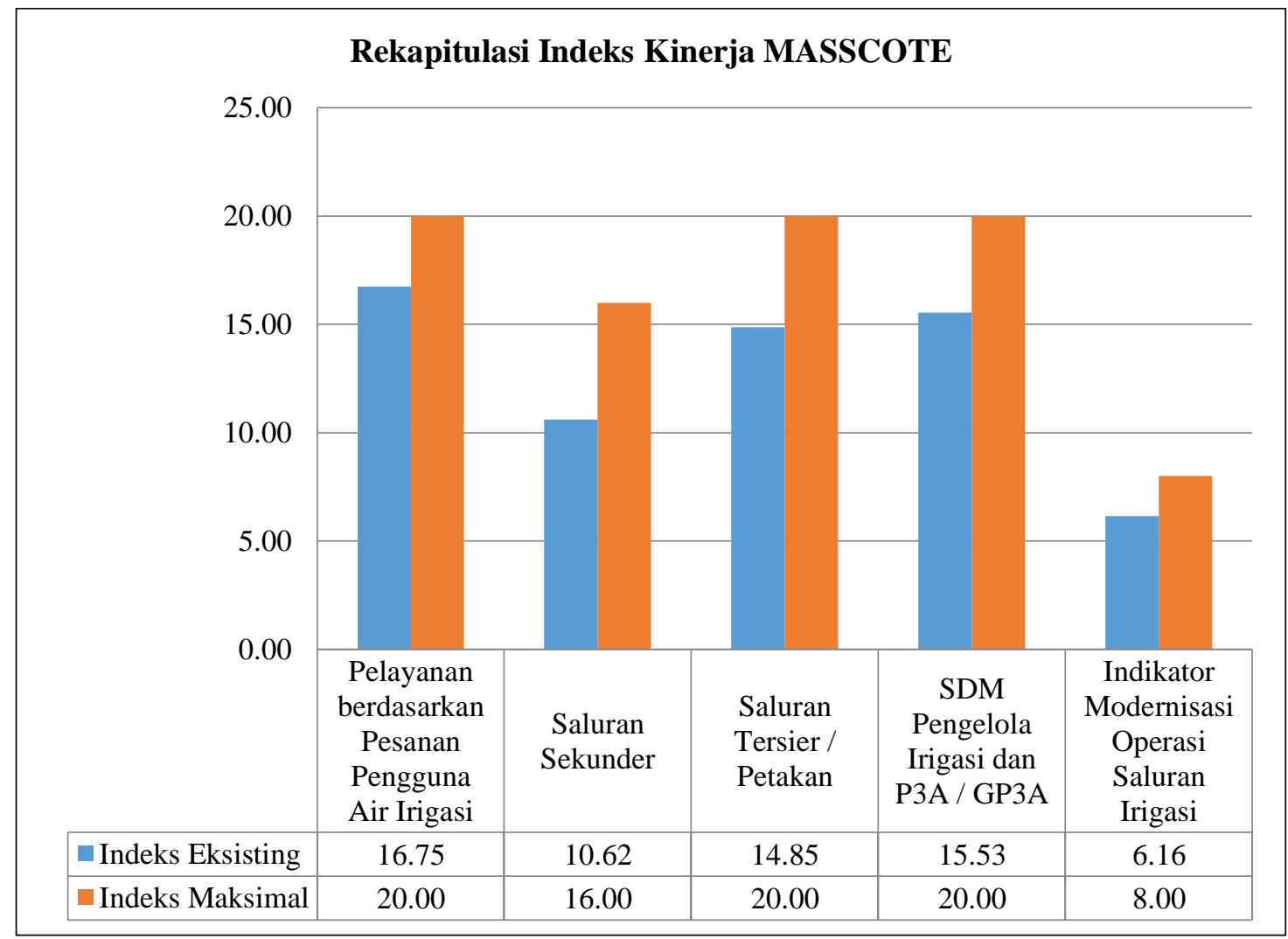

Gambar 2: Indeks Kinerja Sistem Irigasi dengan Pendekatan MASSCOTE

Pada penilaian kondisi kinerja sistem irigasi berdasarkan Metode MASSCOTE dengan evaluasi RAP terdapat 4 aspek yang menyebabkan kinerja dalam kondisi baik yaitu pelayanan berdasarkan pesanan pengguna air irigasi, saluran tersier, SDM pengelola irigasi dan P3A/GP3A, serta indikator modernisasi operasi saluran irigasi. Hal tersebut dikarenakan pada keempat aspek memiliki nilai mutlak (level of service) lebih dari 3, dimana nilai tersebut dapat diartikan bahwa kinerja sistem irigasi berdasarkan Metode MASSCOTE masuk pada kategori Baik. Dan dari ke-5 aspek yang menyebabkan kondisi kurang baik berdasarkan Metode MASSCOTE yaitu pada aspek saluran sekunder. Hal ini disebabkan karena nilai mutlak (level of service) kurang dari 3.

Pada aspek saluran sekunder yang menyebabkan kinerja dalam kondisi kurang baik yaitu pada aspek hardware/perangkat keras bangunan pengukur dimana tingkat pemeliharaan bangunan ukur kurang baik. Selain hal tersebut juga pada aspek kondisi umum saluran sekunder dimana ketersediaan peralatan dan staf kurang memadai.

Pada penilaian kondisi kinerja sistem irigasi berdasarkan Permen PUPR No.12/PRT/M/2015 sangatlah berbeda dengan Metode MASSCOTE. Dimana yang membedakan dari keduanya yaitu pada Permen PUPR No.12/PRT/M/2015 penilaiannya fokus kepada penilaian fisik, sedangkan Metode MASSCOTE penilaiannya fokus kepada penilaian pelayanan irigasi. 


\subsection{Pemodelan dengan Analisis Jalur (Path Analysis)}

Analisis Jalur atau Path Analysis pada penelitian ini dimaksudkan untuk mengetahui pengaruh indikator utama dalam penilaian kinerja sistem Irigasi dengan metode MASSCOTE. Daftar pertanyaan kuesioner variabel indikator utama dalam MASSCOTE meliputi variabel kinerja irigasi MASSCOTE $(\mathrm{Y})$, variabel indikator pelayanan irigasi (X1), variabel indikator P3A (X2), variabel indikator SDM Petugas OP (X3) dan variabel indikator modernisasi OP (X4) [10].

Tabel 4: Rekapitulasi Data Ordinal Jawaban Responden Terhadap Variabel Indikator Utama

\begin{tabular}{cccccc}
\hline Responden & $\mathbf{X}_{\mathbf{1}}$ & $\mathbf{X}_{\mathbf{2}}$ & $\mathbf{X}_{\mathbf{3}}$ & $\mathbf{X}_{\mathbf{4}}$ & $\mathbf{Y}$ \\
\hline 1 & 20,50 & 16,50 & 12,00 & 26,70 & 27,00 \\
2 & 21,00 & 16,50 & 11,60 & 26,30 & 27,60 \\
3 & 21,00 & 15,40 & 11,30 & 26,80 & 26,40 \\
4 & 21,50 & 16,50 & 13,00 & 27,00 & 27,70 \\
5 & 20,60 & 16,50 & 11,20 & 26,70 & 26,90 \\
6 & 20,50 & 16,50 & 12,50 & 27,00 & 26,80 \\
7 & 21,00 & 16,00 & 11,30 & 27,00 & 26,00 \\
8 & 21,50 & 16,00 & 11,30 & 27,00 & 27,00 \\
9 & 20,70 & 15,50 & 11,00 & 27,00 & 26,00 \\
10 & 21,00 & 15,70 & 12,50 & 27,10 & 26,50 \\
11 & 20,50 & 15,30 & 13,00 & 27,30 & 26,00 \\
12 & 21,00 & 15,30 & 11,20 & 27,00 & 26,00 \\
13 & 20,60 & 15,40 & 11,20 & 26,80 & 26,00 \\
14 & 21,00 & 15,60 & 12,00 & 27,10 & 27,00 \\
\hline
\end{tabular}

Skala pemberian nilai dari jawaban responden adalah 1-4 dari setiap pilihan jawaban. Selanjutnya data skoring dirubah menjadi data ordinal sebagaimana tersaji dalam rekapitulasi data ordinal variabel indikator utama pada tabel 5. Selanjutnya dengan bantuan software SPSS 22 diperoleh analisis data yang menghasilkan persamaan jalur sebagai berikut :

$$
\mathrm{Y}=0,420 \mathrm{X}_{1}+0,427 \mathrm{X}_{2}+0,432 \mathrm{X}_{3}-0,446 \mathrm{X}_{4} \text {, dengan } \mathrm{R}^{2} 0,857 \text { atau } 85,7 \% \text {. }
$$

Persamaan tersebut dapat diartikan bahwa besarnya konstribusi pelayanan irigasi $\left(\mathrm{X}_{1}\right)$, indikator P3A $\left(\mathrm{X}_{2}\right)$, indikator SDM petugas $\mathrm{OP}\left(\mathrm{X}_{3}\right)$ dan indikator modernisasi $\mathrm{OP}\left(\mathrm{X}_{4}\right)$ berpengaruh secara simultan yang langsung mempengaruhi kinerja sistem irigasi (Y) yaitu sebesar 0,857 atau $85,7 \%$.

\section{Kesimpulan}

Berdasarkan hasil analisis dan pembahasan dapat diperoleh hasil kesimpulan sebagai berikut:

1. Kinerja sistem irigasi pada Daerah Irigasi Candi berdasarkan Permen PUPR No.12/PRT/M/2015 menunjukkan nilai sebesar 63,16\% (nilai maksimum 100\%) termasuk pada kategori kinerja kurang dan perlu perhatian untuk kinerja sistem irigasi. Hal yang menyebabkan kinerja kurang dan perlu perhatian adalah parameter P3A dengan nilai kondisi eksisting 4,85\%, parameter sarana penunjang dengan nilai kondisi eksisting $4,95 \%$ dan parameter dokumentasi dengan nilai kondisi eksisting $3,05 \%$. 
2. Kinerja sistem irigasi berdasarkan metode MASSCOTE dengan evaluasi RAP menunjukkan 3,04 (nilai maksimal 4) dalam Level of Service termasuk dalam kategori baik untuk kinerja sistem irigasi berdasarkan metode MASSCOTE. Melalui analisis jalur (Path Analysis) didapatkan pemodelan matematika dengan persamaan $\mathrm{Y}=0,420 \mathrm{X} 1+0,427 \mathrm{X} 2+0,432 \mathrm{X} 3-0,446 \mathrm{X} 4$, dengan $\mathrm{R}^{2} 0,857$ atau $85,7 \%$. Dimana variabel indikator utama dalam metode MASSCOTE $\left(\mathrm{X}_{1}, \mathrm{X}_{2}, \mathrm{X}_{3}\right.$ dan $\left.\mathrm{X}_{4}\right)$ berpengaruh secara simultan yang langsung mempengaruhi kinerja sistem irigasi (Y) sebesar 0,857 atau $85,7 \%$.

3. Maka hasil keputusan untuk metode MASSCOTE pada indikator utama yaitu; indikator pelayanan irigasi $\left(\mathrm{X}_{1}\right)$, indikator P3A $\left(\mathrm{X}_{2}\right)$, indikator SDM petugas OP $\left(\mathrm{X}_{3}\right)$ dan indikator modernisasi OP $\left(\mathrm{X}_{4}\right)$ menunjukkan nilai 3,04 bahwa tingkat kinerjanya dalam Level of Service termasuk kategori baik. Pada penilaian kondisi kinerja sistem irigasi berdasarkan Metode MASSCOTE dengan evaluasi RAP terdapat 4 aspek yang menyebabkan kinerja dalam kondisi baik yaitu pelayanan berdasarkan pesanan pengguna air irigasi, saluran tersier, SDM pengelola irigasi dan P3A/GP3A, serta indikator modernisasi operasi saluran irigasi. Sedangkan untuk aspek saluran sekunder termasuk pada kategori kurang baik dikarenakan pada aspek hardware/perangkat keras bangunan pengukur dimana tingkat pemeliharaan bangunan ukur kurang baik. Selain hal tersebut juga pada aspek kondisi umum saluran sekunder dimana ketersediaan peralatan dan staf kurang memadai.

\section{Daftar Pustaka}

[1] S. M. Fachrie, M. Achmad, Samsuar, "Penilaian Kinerja Sistem Irigasi Utama Daerah Irigasi Bantimarung Kabupaten Maros". Sulawesi Selatan: Universitas Hasanuddin, 2019.

[2] Rahajeng, Endah Aryuningsih Tri, "Kinerja Sistem Irigasi Daerah Irigasi (DI) Krisak Kabupaten Wonogiri”. Jawa Barat: Universitas Sebelas Maret, 2012.

[3] Kurniawati, Lutfa, "Inventarisasi Kondisi Jaringan Irigasi Saluran Irigasi Sekunder Pada Daerah Irigasi Taman Sari Wilayah Kerja Pengamat Pengairan Wuluhan Kabupaten Jember". Jember: Universitas Jember, 2017.

[4] I. S. Mulyadi, S. Natasaputra, "Penilaian Kinerja Irigasi Berdasarkan Pendekatan Permen PU NO. 32/2007 Dan Metode Masscote Dengan Evaluasi Rapid Appraisal Procedure (RAP) Di Daerah Irigasi Barubug”. Jawa Barat: Institut Teknologi Bandung, 2014.

[5] C. Mubarok, S. I. Wahyudi, G. D. Asfari, "Penilaian Kinerja Irigasi Berdasarkan Pendekatan Permen PUPR No. 12/PRT/M/2015 Dan Metode Masscote Dengan Evaluasi Rapid Appraisal Procedure (RAP) Di Daerah Irigasi”. Jawa Tengah: Universitas Islam Sultan Agung Semarang, 2016.

[6] Riduwan, Kuncoro \& Engkos Ahmad, "Cara Menggunakan dan Memaknai Analisis Jalur (Path Analysis)". Bandung: Alfabeta, 2010.

[7] Pemerintah Republik Indonesia, "Peraturan Menteri Pekerjaan Umum dan Perumahan Rakyat Nomor 12/PRT/M/2015 tentang Eksploitasi dan Pemeliharaan". Jakarta: Pemerintah Republik Indonesia, 2015.

[8] Winardi, "Kajian Kinerja Sistem Irigasi Di Daerah Irigasi Pandrah Kabupaten Bireuen”. Banda Aceh: Universitas Syiah Kuala, 2019.

[9] Burt, Charles Dr, "Rapid Appraisal Process (RAP) and Benchmarking Explanation and Tools". ITRC Cal Poly California USA, 2001.

[10] Renault, Daniel et al, "Modernizing Irrigation Management - The MASSCOTE Approach". Rome Italy: FAO Irrigation dan Drainage Paper, 2007. 